Malaysian Journal of Social Sciences and Humanities (MJSSH)

Volume 4, Issue 7, November 2019

e-ISSN : 2504-8562

Journal home page:

www.msocialsciences.com

\title{
Tahap Pengetahuan Masyarakat Terhadap Keganasan Rumah Tangga: Kajian Rintis
}

\author{
Nuruaslizawati Binti Ayob' ${ }^{1}$, Siti Hajar Binti Abdul Rauf ${ }^{1}$ \\ ${ }^{1}$ Fakulti Sains Sosial Gunaan, Universiti Sultan Zainal Abidin (UniSZA) \\ Correspondence: Nuruaslizawati Binti Ayob (ayobnuruaslizawati@gmail.com)
}

\begin{abstract}
Abstrak
Keganasan rumah tangga merujuk kepada penyalahgunaan kuasa yang digunakan sama ada oleh suami kepada isteri dan/atau sebaliknya melalui keganasan, ancaman keganasan atau mengawal ekonomi serta kehidupan sosial. Satu kajian rintis dilakukan bertujuan untuk mengenal pasti tahap pengetahuan masyarakat terhadap isu keganasan rumah tangga. Kajian ini melibatkan seramai 50 orang responden telah dipilih secara rawak mudah. Data dikumpul melalui edaran borang soal selidik dan dianalisis menggunakan perisian SPSS dengan menggunakan analisis berbentuk deskriptif untuk mengukur min, sisihan piawai, kekerapan dan peratusan bagi menerangkan tahap pengetahuan masyarakat mengenai isu keganasan rumah tangga. Hasil analisis mendapati bahawa tahap pengetahuan masyarakat mengenai keganasan rumah tangga adalah pada tahap yang sederhana. Dicadangkan agar pihak bewajib melipatgandakan usaha atau inisiatif dengan menguar-uarkan kepada masyarakat khususnya maklumat mengenai keganasan rumah tangga supaya masyarakat pada hari ini lebih peka mengenai isu keganasan rumah tangga.
\end{abstract}

Kata kunci: keganasan rumah tangga, pengetahuan masyarakat

\section{Level of Knowledge Among Community on Domestic Violence: Pilot Test}

\begin{abstract}
Domestic violence refers to abuse that power be used either by the husband to the wife and / or otherwise through violence, threat of violence or controlling the economic and social life. A pilot study carried out in order to determine the level of public knowledge on the issue of domestic violence. This study involved 50 respondents which were selected using a simple random sampling. Data were collected using a questionnaire survey and was performed by SPSS software using descriptive statistical measures mean, standard deviation, frequency, and percentage to describe the level of community knowledge about the issue of domestic violence. The analysis found that the level of knowledge among community is at a moderate level. It is proposed that the authorities expand their efforts or initiatives to get the word out to the public, especially information about domestic violence so that people today are more aware of the issue of domestic violence.
\end{abstract}

Keywords: domestic violence, public knowledge 


\section{Pengenalan}

Keluarga dianggap sebagai suatu sistem di mana individu perlu menghormati antara satu sama lain. Keluarga yang lengkap adalah dengan hadirnya ibu, bapa dan anak-anak yang tinggal di dalam satu rumah. Namun, terdapat juga institusi yang melibatkan keluarga yang luas iaitu dengan kehadiran datuk, nenek, saudara-mara lain. Mereka berfungsi sebagai tempat yang selamat untuk berkembang dan bertindak dalam memberi sokongan emosi dan material. Struktur dalam keluarga ditentukan mengikut pangkat kedudukan mereka dalam keluarga. Sebagai contoh, pembangunan manusia boleh dipertingkat dengan memperkaya kehidupan keluarga (Sangwan, 2014). Mereka berfungsi sebagai penghubung antara satu sama lain dalam mewaujudkan suasana yang harmoni dan sejahtera dalam keluarga.

Menurut Norlina (2019), individu yang membesar dalam keluarga yang tidak berfungsi dengan baik sering mengalami masalah keluarga sendiri apabila dewasa. Keganasan dipelajari secara langsung atau tidak langsung melalui tingkah laku ahli keluarga. Kajian mendapati bahawa seseorang yang berperilaku agresif adalah mereka yang pernah menyaksikan atau mengalami keganasan dalam keluarga (Hyde-Nolan dan Juliao, 2012).

\section{Literatur Kajian}

Keganasan rumah tangga telah dikenalpasti sebagai satu masalah sosial. Masalah ini telah memberi pengaruh kepada kesejahteraan psikologi mereka. Masalah ini sering digambarkan sebagai masalah yang berpusat pada keluarga dan umumnya difahami sebagai satu tingkah laku kasar dan paksaan (abdul ghani et al, 2016). Persepsi budaya Malaysia melihat lelaki berperanan dalam mengurus hal kekeluargaan berbanding wanita yang dilihat sebagai "orang rumah" yang berperanan sebagai "pengasuh" anak-anak. Keganasan rumahtangga bukan sahaja melibatkan wanita (Semahegn \& Mengistie, 2015) tetapi lelaki juga didapati disalahgunakan oleh pasangan mereka (Reingle et al., 2013). Menurut De Wall, Kikkert, Kleinhesselink dan Goudriaan, (2017), lelaki kebiasaan disalahgunakan oleh orang yang tidak dikenali, tetapi wanita disalahgunakan oleh pasangan atau bekas pasangan mereka. Speizer (2010) menyatakan keganasan terhadap wanita sering dikaitkan dengan sikap lelaki.

Keganasan melibatkan sentuhan, serangan, gangguan, kekejamaan fizikal dan mental, atau apa-apa tingkah laku yang memberi kesan kepada mangsa. Kebanyakan wanita menjadi mangsa keganasan samada dari segi psikologi atau fizikal, yang mana membawa kepada masalah kesihatan yang serius bagi mereka (Flury dan Nyberg, 2010). Tingkah laku agresif seperti fizikal (menampar, memukul, menendang, serangan bersenjata), emosi (mengejar, mengawal, menghina, menghalang daripada berhubungan dengan keluarga atau rakan), seksual (rogol, memaksa dalam melakukan hubungan seksual) atau ekonomi (mengawal ekonomi) (Abdul Ghani, 2014; Cao et al, 2011; Salari dan Ramsay et al, 2012).

Pengalaman selain daripada keganasan fizikal, emosi, seksual dan ekonomi, keganasan turut dipengaruhi oleh norma budaya, sejarah dan politik. Statistik Polis Diraja Malaysia (PDRM) dari tahun 2010 hingga Mac 2017 mendapati bahawa sebanyak 23212 kes keganasan rumah tangga dilaporkan melibatkan wanita sebagai mangsa.

Keganasan rumah tangga mungkin berbeza dari sudut pandang negara atau budaya (Tonsing, 2014) tetapi berlaku di semua negara tanpa mengira etnik, kelompok sosial, ekonomi, agama atau budaya (Pyles dan Postmus, 2004). Keganasan mungkin boleh berlaku sekali, atau mungkin berlaku dalam corak yang berulang dan mampu meningkat selama tempoh sebulan atau setahun (Goldstein, 2007). Kebanyakan wanita dalam masyarakat telah menjadi mangsa penghinaan, penyeksaan, eksplotasi dan juga berfungsi sebagai sumber kepuasan nafsu peribadi.

Walaupun laporan keganasan rumah tangga ditahap yang membimbangkan, namun tahap keganasan sebenar tidak dapat diandaikan dengan tepat. Pelbagai kajian yang telah dilakukan mendapati pengetahuan mengenai pengalaman wanita didera masih kurang (abdul ghani et al, 2016). Hal ini 
demikian kerana, tidak mudah bagi seseorang yang terlibat untuk bercakap tentang pengalaman mereka atau meminta bantuan. Oleh itu, tujuan kajian ini adalah untuk mendapatkan pemahaman masyarakat tentang keganasan rumah tangga.

\section{Metod Kajian}

Kajian ini dijalankan untuk mengetahui tahap pengetahuan masyarakat di Kuala Terengganu. Kajian ini menggunakan kaedah kuantitatif. Sebanyak 50 soal selidik diedarkan dan telah dijawab sepenuhnya. Menurut Mitchell dan Jolley, (2010) soal selidik merupakan satu set yang dibentuk secara khusus di mana responden membaca dan menulis jawapan. Tujuan soal selidik diberikan adalah untuk mengumpul maklumat berkaitan kajian. Jackson (2015), berpendapat bahawa soal selidik adalah untuk mengukur bagaimana seseorang bertindak, berfikir atau merasakan sesuatu. Manakala, rujukan daripada buku, internet digunakan bagi memperoleh data sekunder.

Kajian ini merupakan kajian rintis yang dilakukan terhadap masyarakat di Kuala Terengganu. Kebolehpercayaan bagi kajian rintis item ini adalah 0.914. Menurut Mohd Majid Kontang (2000), nilai alpha melibihi 0.6 dikategorikan sebagai item yang boleh dipercayai dan boleh digunaakan dalam kajian sebenar.

Tahap pengetahuan telah diukur melalui 15 item. Skala likert telah digunakan dan bersesuaian dengan pernyataan dalam konteks pengetahuan iaitu (1) sangat tidak setuju sehingga skala (5) sangat setuju. Data telah dianalisis menggunakan perisian SPSS versi 17 dengan menumpukan kaedah statistik deskriptif iaitu min, sisihan piawai, kekerapan dan peratus kekerapan. Bagi menginterpretasi tahap pengetahuan terhadap isu keganasan rumah tangga, skor min dikodkan kepada tiga tahap iaitu tahap rendah, sederhana dan tinggi.

Jadual 1: Skala Interprestasi Skor Min

\begin{tabular}{lcc}
\hline Bil & Julat skor min & Tahap \\
\hline 1 & $1.00-2.33$ & Rendah \\
2 & $2.34-3.66$ & Sederhana \\
3 & $3.67-5.00$ & Tinggi
\end{tabular}

Sumber: Pallant (2007)

\section{Dapatan Kajian}

\section{Tahap pengetahuan masyarakat mengenai keganasan rumah tangga}

Merujuk kepada Jadual 2, didapati bahawa tahap pengetahuan masyarakat mengenai keganasan rumah tangga adalah berada pada tahap sederhana, iaitu pada nilai Min 3.62 dan nilai sisihan piawai 1.048. Item ini adalah untuk melihat sejauh manakah tahap pengetahuan masyarakat terhadap isu rumah tangga. Isu rumah tangga yang dimaksudkan adalah perkara-perkara yang sering digunakan dalam sebarang tindakan keganasan yang dikenakan oleh pasangan samada dalam bentuk fizikal, emosi, ekonomi dan seksual.

Terdapat 15 item pengetahuan telah diuji menggunakan kaedah deskriptif. Sebanyak 9 item pengetahuan berada di tahap tinggi, dan 6 item berada di tahap sederhana. Hal ini menunjukkan bahawa respondan yang terlibat dalam kajian ini mempunyai nilai tahap pengetahuan yang sederhana. Menurut jadual 2, min item yang sederhana paling tinggi ialah 3.62 "Keganasan rumah tangga ialah corak keganasan, penderaan, ugutan yang digunakan untuk mengawal atau mengekalkan kuasa ke atas pasangan yang sedang atau dalam hubungan intim". 
Jadual 2: Tahap Pengetahuan

\begin{tabular}{|c|c|c|c|c|}
\hline Item & Pernyataan & $\mathrm{N}$ & Min & $\begin{array}{l}\text { Sisihan } \\
\text { piawai }\end{array}$ \\
\hline D1 & $\begin{array}{l}\text { Keganasan rumah tangga termasuk keganasan emosi dan } \\
\text { lisan }\end{array}$ & 50 & 4.14 & .833 \\
\hline D2 & $\begin{array}{l}\text { Keganasan bermula daripada keganasan emosi diikuti } \\
\text { keganasan fizikal }\end{array}$ & 50 & 4.08 & 1.007 \\
\hline D3 & $\begin{array}{l}\text { Keganasan rumah tangga ialah keganasan fizikal yang } \\
\text { menyebabkan kemudaratan pada anggota badan }\end{array}$ & 50 & 4.02 & 1.040 \\
\hline D4 & Keganasan rumah tangga termasuklah keganasan seksual & 50 & 3.88 & 1.118 \\
\hline D5 & Keganasan rumah tangga seringkali berlaku di Malaysia & 50 & 3.84 & 976 \\
\hline D6 & $\begin{array}{l}\text { Keganasan rumah tangga adalah keganasan secara sengaja } \\
\text { dengan meletakkan mangsa di dalam ketakutan }\end{array}$ & 50 & 3.80 & 1.069 \\
\hline D7 & $\begin{array}{l}\text { Mengurung atau menahan tanpa kerelaan adalah } \\
\text { dikategorikan sebagai keganasan rumah tangga. }\end{array}$ & 50 & 3.78 & 1.075 \\
\hline D8 & $\begin{array}{l}\text { Mangsa yang terlibat dalam keganasan rumah tangga tidak } \\
\text { menghiraukan keselamatan anak-anak mereka }\end{array}$ & 50 & 3.78 & 1.166 \\
\hline D9 & $\begin{array}{l}\text { Keganasan rumah tangga termasuklah melakukan khianat } \\
\text { atau merosakkan harta dengan niat menyebabkan kesedihan } \\
\text { atau kegusaran }\end{array}$ & 50 & 3.72 & .991 \\
\hline D10 & $\begin{array}{l}\text { Keganasan rumah tangga ialah corak keganasan, penderaan, } \\
\text { ugutan yang digunakan untuk mengawal atau mengekalkan } \\
\text { kuasa ke atas pasangan yang sedang atau dalam hubungan } \\
\text { intim. }\end{array}$ & 50 & $\begin{array}{l}3.62 \\
(\mathrm{~s})\end{array}$ & 1.067 \\
\hline D11 & $\begin{array}{l}\text { Keganasan rumah tangga adalah mengenai kuasa dan } \\
\text { kawalan }\end{array}$ & 50 & 3.56 & .972 \\
\hline D12 & $\begin{array}{l}\text { Keganasan rumah tangga adalah mengancam dengan } \\
\text { keganasan walaupun bukan dengan keganasan fizikal } \\
\text { sebenar }\end{array}$ & 50 & 3.46 & 1.110 \\
\hline D13 & $\begin{array}{l}\text { Seseorang yang melakukan keganasan fizikal kepada } \\
\text { pasangannya adalah "pesakit mental }\end{array}$ & 50 & 3.42 & 1.032 \\
\hline D14 & $\begin{array}{l}\text { Keganasan rumah tangga seringkali berlaku kepada } \\
\text { pasangan yang telah lama mendirikan rumah tangga. }\end{array}$ & 50 & 2.62 & 1.176 \\
\hline \multirow[t]{2}{*}{ D15 } & $\begin{array}{l}\text { Keganasan rumah tangga seringkali berlaku kepada } \\
\text { pasangan yang baru mendirikan rumah tangga. }\end{array}$ & 50 & 2.60 & 1.088 \\
\hline & & 50 & 3.62 & 1.048 \\
\hline
\end{tabular}

\section{Perbincangan}

Masalah sosial ini dapat membentuk satu persepsi dimana pada awalnya masyarakat tidak menganggap isu keganasan ini sebagai isu yang serius dan mengganggap ini satu rahsia yang perlu disembunyikan. Keadaan ini menunjukkan bahawa respondan masih kurang berpengetahuan atau tidak peka persekitaran sosial terhadap sesetengah isu keganasan rumah tangga. Kajian Bellingham-Whatcom County Commission against Domestic Violence, (2002) mendapati bahawa halangan dalaman seperti emosi, sikap, pengetahuan dan kesedaran mereka tentang masalah keganasan rumah tangga adalah penghalang bagi mereka untuk mencari jalan keluar bagi masalah ini.

Keganasan bukan sahaja melibatkan jantina, tetapi ia terjadi tanpa mengira agama, bangsa, umur, namun masalah ini sering diabaikan atau dinafikan haknya. Mangsa yang mengalami semua bentuk keganasan sukar untuk dibuktikan melainkan kecederaan fizikal (Abdul Ghani, 2014). Kecederaan daripada keganasan yang melibatkan keganasan fizikal dapat dilihat dengan pandangan mata kasar, manakala kecederaan emosi boleh meninggalkan parut yang dalam. 
Majoriti masyarakat melihat keganasan antara pasangan suami isteri adalah masalah peribadi yang tidak boleh diganggu (Khan., 2015). Walaupun terdapat banyak kajian yang dilakukan, tetapi masalah ini masih mencari jalan penyelesaian dan ditahap yang membimbangkan pada hari ini. Menurut Aziz, Idris, Ishak, Wahid, \& Yazid (2018) kekerapan dan keterangan tentang keganasan rumah tangga di Malaysia adalah tidak diketahui sepenuhnya. Kajian ini menujukkan tahap pengetahuan masyarakat tentang keganasan rumah tangga adalah di tahap sederhana.

Kekurangan ilmu pengetahuan mengenai keganasan rumah tangga merupakan halangan utama dalam membuat keputusan. Menurut Webster, Pennay, Bricknall, Diemer, Flood, Powell, Politoff dan Ward (2014), pemahaman terhadap keganasan terhadap wanita dan perilaku mereka mempunyai kesan yang signifikan terhadap kegansan rumah tangga. Keganasan rumah tangga turut dikaitkan dengan corak tingkah laku yang berterusan dengan tujuan untuk mengawal. Kawalan diri yang lemah sehingga menimbulkan kemarahan dianggap pencetus kepada tindakan ganas (Howells, Day, \& Thomas-Peter, 2004). Selain itu, bentuk keganasan yang kurang jelas dan kepercayaan terhadap masalah ini menyukarkan seseorang mengambil keputusan untuk meninggalkan pasangan walaupun pelbagai input seperti ceramah, seminar, pemplets, dan lain-lain telah dibekalkan.

World Health Organization (2002), mencadangkan terdapat tiga tahap pencegahan yang perlu dinilai sebelum berlakunya keganasan. (i) pendekatan bertujuan untuk mencegah keganasan sebelum berlaku. Sebagai contoh, memberitahu kepada masyarakat tentang konflik dan mewujudkan kesedaran terutama kepada wanita yang terdedah kepada keganasan. (ii) penglibatan pihak sekunder untuk mengurangkan kekerapan keganasan. Sebagai contoh, memberi tumpuan segera terhadap setiap keganasan yang berlaku seperti perkhidmatan kecemasan atau rawatan untuk penyakit kelamin selepas rogol. (iii) pencegahan daripada pihak ketiga. Sebagai contoh, memberi tumpuan kepada penjagaan jangka panjang seperti pemulihan dan mengintegrasi, mengurangkan trauma atau kecacatan jangka panjang yang berkait dengan keganasan.

\section{Kesimpulan}

Memahami sikap dan sejauh mana pengetahuan umum masyarakat terhadap isu keganasan rumah tangga adalah penting kerana persepsi masyarakat dapat dijadikan pengukur kepada keganasan dan membentuk tindak balas seseorang. Buang (2017), menyatakan bahawa mesej tentang keganasan rumah tangga perlu dikongsi untuk mendidik dan mengubah persepsi masyarakat yang mengelirukan. Kajian ini mendapati bahawa masyarakat masih belum menguasai sepenuhnya tentang makna yang tersurat disebalik keganasan rumah tangga. Oleh itu, keperluan untuk campurtangan adalah penting dalam mengurangkan risiko keganasan dan meningkatkan kesejahteraan mereka. Selain itu, kajian ini dilihat penting untuk dikaji kerana ia bertindak balas terhadap pembentukan undang-undang dan dasar negara.

\section{Rujukan}

Abdul Ghani, M., (2014). Exploring domestic violence experiences from the perspective of abused women in Malaysia. Loughborough University

Abdul Ghani. M., N.A. Ahmad., dan A. Mohamad. (2016). Profiles of Domestic Violence Victims and Perpetrators: A Qualitative Research Perspective. Journal of Advanced Research in Social and Behavioural Sciences ISSN (online): 2462-1951 Vol. 4, No. 1. Pages 43-50.

Aziz, N. N. A., Idris, S. A. M., Ishak, M., Wahid, N. A., \& Yazid, Z. N. A. (2018a). Factors affecting domestic violence against women: a conceptual model and research propositions. International Journal for Studies on Children, Women, Elderly And Disabled, 4(June), 191198.

Bellingham-Whatcom County Commission against Domestic Violence. (2002). Community survey project: Factors that influence disclosure of domestic abuse to providers. Minnesota Center Against Violence and Abuse [MINCAVA]: Minnesota. 
Cao, Y. P., Zhang, Y. L., Chang, D. F., Yang, S. C., \& Wang, G. Q. (2011). Correlations between selfreported symptoms and psychosocial factors of perpetrators with domestic violence in China: a population-based sample. Chinese medical journal, 124(4), 546-550.

De Waal, M. M., Dekker, J. J., Kikkert, M. J., Kleinhesselink, M. D., \& Goudriaan, A. E. (2017). Gender differences in characteristics of physical and sexual victimization in patients with dual diagnosis: a cross-sectional study. BMC psychiatry, 17(1), 270.

Flury, M., \& Nyberg, E. (2010). Domestic violence against women: definitions, epidemiology, risk factors and consequences. Swiss medical weekly, 140(3536).

Goldstein, M. (2007). Seeking protection from domestic violence. OSCE.

Howells, K., Day, A., \& Thomas-Peter, B. (2004). Changing violent behaviour: Forensic mental health and criminological models compared. Journal of Forensic Psychiatry \& Psychology, 15(3), 391406.

Hyde-Nolan, M. E., \& Juliao, T. (2012). Family violence: what health care providers need to know. Chapter 2: Theoretical Basis for Family Violence.

Jackson, S. L. (2015). Research methods and statistics: A critical thinking approach. Cengage Learning.

Noralina, O., (2019). Pengenalan Kerja Sosial Keluarga. Universiti Malaya. Kuala Lumpur.

Mohd Majid Konting (2000), Kaedah Penyelidikan Pendidikan. Kuala Lumpur: Dewan Bahasa dan Pustaka.

Mitchell, M. L., \& Jolley, J. M. (2010). Research design explained: Instructor's edition (7th ed.). Belmont, CA,: Wadsworth/Cengage Learning.

Khan, A. R. (2015). Domestic Violence against Women in Bangladesh: A Review of the Literature and the Gaps to fill-in by Future Interventions. Khazar Journal of Humanities and Social Sciences, 18(3), 57-81

Pallant, J. (2007) SPSS Survival Manual: A Step by Step Guide to Data Analysis Using SPSS for Windows. 3rd Edition, McGraw Hill Open University Press, New York.

Pyles, L., \& Postmus, J. L. (2004). Addressing the problem of domestic violence: How far have we come?. Affilia, 19(4), 376-388.

Ramsay, J., Rutterford, C., Gregory, A., Dunne, D., Eldridge, S., Sharp, D., \& Feder, G.(2012). Domestic violence: knowledge, attitudes, and clinical practice of selected UK primary healthcare clinicians. Br J Gen Pract, 62(602), e647-e655.

Reingle, J. M., Staras, S. A. S., Jennings, W. G., Branchini, J., \& Maldonado-molina, M. M. (2013). The Relationship Between Marijuana Use and Intimate Partner Violence in a Nationally Representative, Longitudinal Sample. Journal of Interpersonal Violence, 27(8), 1 -13

Salari, Z., \& Nakhaee, N. (2008). Identifying types of domestic violence and its associated risk factors in a pregnant population in Kerman hospitals, Iran Republic. Asia Pacific Journal of Public Health, 20(1), 49-55.

Semahegn, A., \& Mengistie, B. (2015). Domestic violence against women and associated factors in Ethiopia; systematic review. Reproductive health, 12(1), 78.

Speizer, I. S. (2010). Intimate partner violence attitudes and experience among women and men in Uganda. Journal of interpersonal violence, 25(7), 1224-1241.

Sangwan, K. S. (2014). Domestic Violence Against Women: A Sociological Study. Department of Sociology Maharshi Dayanand University Rohtak

Tonsing, J. (2014). A study of domestic violence among south Asian women in Hong Kong (Doctoral dissertation, Royal Holloway, University of London). (R.23-penulis asal)

Webster K, Pennay P, Bricknall R, Diemer K, Flood M, Powell A, Politoff V \& Ward A (2014). Australians' attitudes to violence against women: Full technical report, Findings from the 2013 National Community Attitudes towards Violence Against Women Survey (NCAS). Melbourne: Victorian Health Promotion Foundation.

World Health Organization (2002). World Report on Violance and Health. http://www.who.int/violence_injury_prevention/violence/world_report/en/index.html 